\title{
Antibiose $\epsilon$ estanqueidade do concreto com o uso de aditivo cristalino antimicrobiano para estruturas de saneamento
}

\author{
EMILIO MINORU TAKAGI - Doutorando E DiReTOR TÉcNICO \\ Instituto Tecnológico de Aeronáutica (ITA) - Penetron Internacional
}

CRISTIANO MARTINS QUINTÃO - MESTRE E ENGENHEIRO CIVIL

Companhia de Saneamento de Minas Gerais (COPASA)

\author{
SÁVIO NUNES BONIFÁCIO - Mestre E ENGeNheIRO CIVIL \\ UFMG - Companhia de Saneamento de Minas Gerais (COPASA)
}

\section{CLÁUDIO NEVES OURIVES - DIRETOR}

Penetron Brasil Ltda.

MARYANGELA geIMBA LIMA - Professora Doutora Titular

Instituto Tecnológico de Aeronáutica (ITA)

\section{RESUMO}

ESTE ARTIGO APRESENTA O MECANISMO DE FORMAÇÃO DO ÁCIDO SULFÚRICO $\left(\mathrm{H}_{2} \mathrm{SO}_{4}\right)$ BIOGÊNICO, OS FATORES DE INFLUÊNCIA NA REAÇÃO E USO DO ADITIVO CRISTALINO (CA), EM CONJUNTO COM O ADITIVO ANTIMICROBIANO (CA-A), COMO UMA ESTRATÉGIA PARA MITIGAR E PREVENIR A BIODEGRADAÇÃO DO CONCRETO. O CA-A APRESENTA PROPRIEDADES DE ANTIBIOSE E DE ESTANQUEIDA-
DE, QUE EVITAM A FORMAÇÃO DE BIOFILMES ANAERÓBICOS E AERÓBICOS, ONDE OCORRE A COLONIZAÇÃO POR BACTÉRIAS DOS TIPOS REDUTORAS DE SULFATOS (BRS) E OXIDANTES DE SULFATOS (BOS) EM ESTRUTURAS DE SANEAMENTO, QUE RESULTA EM PROBLEMAS DE CORROSÃO, EMANAÇÃO DE MAUS ODORES E TOXIDADE DO MEIO.

Palavras-chave: biodeterioração do concreto, ácido sulfúrico biogênico, aditivo cristalino antimicrobiano, reabilitação.

\section{INTRODUÇÃO}

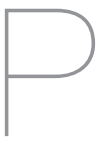

ela primeira vez na história do saneamento básico brasileiro, vislumbra-se a chance de reverter o cenário atual com o Novo Marco Regulatório do Saneamento Básico, aprovado e sancionado em 2020, que pode potencializar ações para atingir metas de universalização de 99\% de cobertura para abastecimento de água e 90\% de cobertura e tratamento de esgoto até 31 de dezembro de 2033. As mudanças trazidas pelo novo marco facilitam investimentos estimados na ordem de 700 bilhões em obras de saneamento e criam um ambiente favorável à abertura e à participação do setor privado, com impactos positivos na economia e na geração de empregos na construção civil, nos 5.570 municípios espalhados pelo Brasil.

O principal desafio é a viabilidade do saneamento de cidades com pouca atratividade para a iniciativa privada. $\mathrm{O}$ texto do novo marco permite a organização de municípios em "aglomerados", numa abordagem mais regional, o que pode trazer atratividade comercial e possibilitar a realização de subsídios cruzados, quando necessário. Representa um avanço necessário da transição do público para uma participação privada mais relevante, que lançariam novas metas de operação, qualidade e investimentos. Esta oportunidade de expansão deve abrir espaço para aprimoramentos tecnológicos, como os aditivos cristalinos redutores de permeabilidade com propriedades antimicrobianas, contribuindo para a construção de estruturas de saneamento em concreto estanques, mais duráveis, e mais sustentáveis.

Neste sentido, um acordo de cooperação técnica, de doze meses, em construção entre a Companhia de Saneamento de Minas Gerais (COPASA), a Penetron Brasil e o Instituto Tecnológico de Aeronáutica (ITA), objetiva avaliar as manifestações patológicas 
por biodeterioração nas estruturas das estações de tratamento de esgoto (ETEs), construídas em concreto armado ou ferrocimento, bem como aplicar prova de conceito ${ }^{1}$ relativo à eficiência do uso do aditivo cristalino antimicrobiano, dosado no concreto armado ou na argamassa do ferrocimento, visando recuperar, proteger e ampliar a durabilidade da ETEs e reduzir o custo de investimento e manutenção destes ativos.

\section{FORMAÇÃO DO ÁCIDO SULFÚRICO BIOGÊNICO (ASB)}

O ciclo do sulfeto é um processo no qual o sulfato e outros compostos à base de enxofre, presente no esgoto, são reduzidos através da ação de um grupo de bactérias anaeróbias estritas, denominadas bactérias sulforedutoras (BRS), formando como produto final o sulfeto de hidrogênio $\left(\mathrm{H}_{2} \mathrm{~S}\right)$ dissolvido no líquido do esgoto (Bonifácio, Quintão e

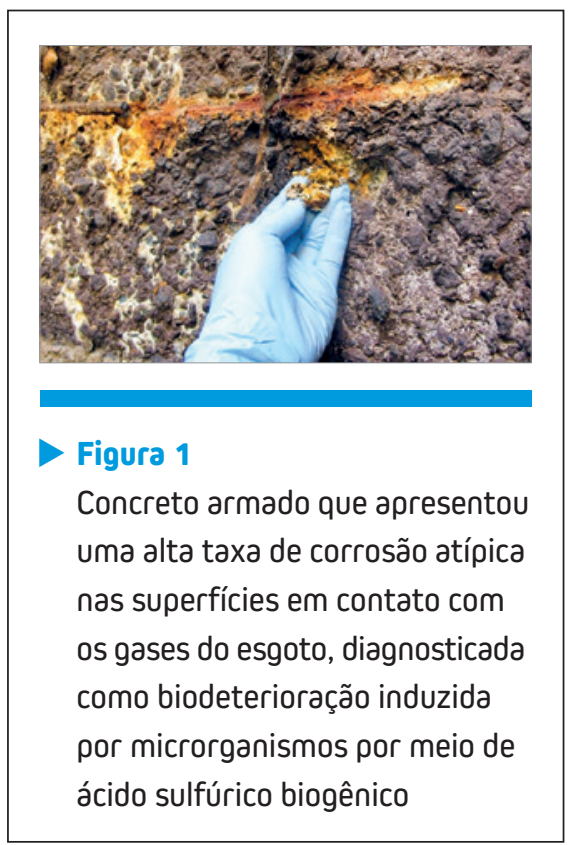

Tabela 1 - Agressividade do esgoto em relação ao concreto

\begin{tabular}{|cccc|}
\hline \multicolumn{2}{c}{ Ambiente agressivo } & Referência & Resultados \\
\hline pH & $<5,5$ & NBR 12655:2015 & 7,2 (neutro) \\
\hline Concentração de cloretos & $>1.000$ ppm & BS EN 1008:2002 & 100 ppm \\
\hline Concentração de sulfatos & $>1.500$ ppm & NBR 12655:2015 & 25 ppm \\
\hline
\end{tabular}

Cardoso 2021). O mecanismo de gatiIho é a turbulência do fluxo do esgoto, que liberam os gases $\mathrm{H}_{2} \mathrm{~S}$ e $\mathrm{CO}_{2}$, que tendem a condensar-se sobre a parede úmida do concreto, diminuindo e neutralizando o pH desta superfície, de forma abiótica. A redução do $\mathrm{pH}$ da superfície para valores abaixo a 9 apresenta condições para a proliferação de diversas famílias de bactéria oxidantes de sulfatos (BOS), que se manifestam através da formação de ácido sulfúrico biogênico (ASB) a partir do $\mathrm{H}_{2} \mathrm{~S}$. Por isso, a alta taxa de corrosão atípica nas superfícies em contato com os gases do esgoto foi diagnosticada como uma biodeterioração induzida por microrganismos por meio de ASB (Figura 1).

Sendo assim, é de grande importância compreender as propriedades de antibiose e de estanqueidade proporcionadas pela dosagem do CA-A no concreto, para prevenir e mitigar a formação dos biofilmes anaeróbicos e aeróbicos que propiciam sua colonização por BRS e BOS. A ASB, produzida pelas bactérias oxidantes, é extremamente agressiva ao concreto, uma vez que ataca a pasta cimentícia, desmineralizando os produtos de hidratação do cimento, especificamente o hidróxido de cálcio e os cristais de silicatos de cálcio hidratados (C-S-H), resultando na perda de coesão do cobrimento do concreto e também redução de seu pH (Quintão, et al. 2020).

\section{I Análise química do esgoto}

Uma análise química típica indica que o esgoto não deve ser uma fonte

Tabela 2 - Zonas da camada de lodo que formam o $\mathrm{H}_{2} \mathrm{~S}_{\text {aquoso }}$ no esgoto

\begin{tabular}{|c|c|c|}
\hline Zona & Mecanismo & $\begin{array}{l}\text { Oxigênio } \\
\text { dissolvido }\end{array}$ \\
\hline Aeróbica & $\begin{array}{c}\text { Em contato com o esgoto, na zona aeróbica, proliferam } \\
\text { bactérias oxidantes de sulfatos (BOS), que consomem o } \\
\text { oxigênio dissolvido no esgoto }\end{array}$ & $\mathrm{OD}>0,1 \mathrm{mg} / \mathrm{L}$ \\
\hline Anaeróbica & $\begin{array}{l}\text { Zona anaeróbica, onde proliferam as bactérias redutoras de } \\
\text { sulfato (BRS), essas consomem gradualmente os nutrientes: } \\
\text { sulfatos e matéria orgânica e geram } \mathrm{H}_{2} \mathrm{~S}_{\text {aquoso }}\end{array}$ & $\mathrm{OD}<0,1 \mathrm{mg} / \mathrm{L}$ \\
\hline Inerte & $\begin{array}{l}\text { A concentração de nutrientes se aproxima de zero na parede } \\
\text { de concreto e as bactérias BRS se tornam inativas. } \\
0 \text { concreto submerso no lodo não é atacado }\end{array}$ & $\begin{array}{l}\mathrm{OD}<0,1 \mathrm{mg} / \mathrm{L} \\
\text { Nutrientes } \approx 0\end{array}$ \\
\hline
\end{tabular}

\footnotetext{
A PROVA DE CONCEITO, PROOF OF CONCEPT OU POC, É APLICADA, NO QUE SE REFERE ÀS CARACTERÍSTICAS, QUALIDADE, FUNCIONALIDADE, DESEMPENHO DE UM PRODUTO DIANTE DE UMA LICITAÇÃO. ASSIM, A PROVA DE CONCEITO DESTINA-SE A PERMITIR QUE A COPASA CONFIRME A EFETIVA ADEQUACÃO DO ADITIVO CRISTALINO ANTIMICROBIANO DENTRO DE UM PROCESSO LICITATÓRIO PARA A PROTEÇÃO E A REABILITAÇÃO DE ESTRUTURAS DE SANEAMENTO.
} 


\section{Tabela 3 - Fatores que afetam a formação de $\mathrm{H}_{2} \mathrm{~S}_{\text {aquoso }}$ no esgoto}

\begin{tabular}{|c|c|c|}
\hline Fator & Mecanismo & Influência \\
\hline \multirow{3}{*}{$\begin{array}{l}\text { Tempo de } \\
\text { retenção do } \\
\text { esgoto }\end{array}$} & $\begin{array}{c}\text { Tempo de retenção > } 30 \text { min estimula a sedimentação de uma camada de lodo, } \\
\text { onde proliferam as BRS. }\end{array}$ & \multirow{3}{*}{ Aumenta $\mathrm{H}_{2} \mathrm{~S}_{\text {aquoso }}$ no esgoto } \\
\hline & $\begin{array}{l}\text { Tempo de retenção maior tende a esgotar o OD no esgoto } \\
\text { e aumentar a liberação de } \mathrm{H}_{2} \mathrm{~S}_{\text {aquoso }} \text { pela camada de lodo }\end{array}$ & \\
\hline & $\begin{array}{l}\text { Tempo de retenção longo resulta em uma camada de lodo solta que facilita } \\
\text { a penetração dos nutrientes para a ZONA ANAERÓBICA }\end{array}$ & \\
\hline \multirow{2}{*}{$\begin{array}{l}\text { Temperatura } \\
\text { do esgoto }\end{array}$} & $\begin{array}{l}\text { Temperaturas }>15^{\circ} \mathrm{C} \text { aumentam a atividade metabólica } \\
\text { microbiana das BRS na ZONA ANAERÓBICA }\end{array}$ & \multirow{2}{*}{ Aumenta $\mathrm{H}_{2} \mathrm{~S}_{\text {aquoso }}$ no esgoto } \\
\hline & $\begin{array}{l}\text { Aumento da temperatura diminui a solubilidade do OD no esgoto } \\
\text { e aumenta a liberação de } \mathrm{H}_{2} \mathrm{~S}_{\text {aquoso }} \text { pela camada de lodo }\end{array}$ & \\
\hline $\begin{array}{c}\text { Demanda } \\
\text { bioquímica de } \\
\text { oxigênio (DBO) }\end{array}$ & $\begin{array}{l}\text { Alta DBO acelera a atividade bacteriana e o consumo do OD, } \\
\text { e aumenta a liberação de } \mathrm{H}_{2} \mathrm{~S}_{\text {aquoso }} \text { pela camada de lodo. }\end{array}$ & Aumenta $\mathrm{H}_{2} \mathrm{~S}_{\text {aquoso }}$ no esgoto \\
\hline $\begin{array}{c}\text { Oxigênio } \\
\text { dissolvido (OD) }\end{array}$ & $\begin{array}{l}\text { Maiores taxas de OD no efluente impedem que } 0 \mathrm{H}_{2} \mathrm{~S}_{\text {aquosos }} \text {, formado na ZONA ANAERÓBICA do lodo, } \\
\text { escape e seja liberado para o esgoto, pois se oxida antes na ZONA AERÓBICA do lodo }\end{array}$ & Diminui $\mathrm{H}_{2} \mathrm{~S}_{\text {aquoso }}$ no esgoto \\
\hline \multirow{4}{*}{$\begin{array}{l}\text { Velocidade de } \\
\text { fluxo do esgoto }\end{array}$} & $\begin{array}{l}\text { Quando é respeitada a velocidade mínima de projeto de 0,6 m/s, } \\
\text { NÃO deve ocorrer a sedimentação de uma camada de lodo. }\end{array}$ & Diminui $\mathrm{H}_{2} \mathrm{~S}_{\text {aquoso }}$ no esgoto \\
\hline & $\begin{array}{l}\text { Velocidades }>1,5 \mathrm{~m} / \mathrm{s} \text { estimulam a aeração e aumentam a oxidação do } \mathrm{H}_{2} \mathrm{~S}_{\text {aquosos }} \\
\text { resultando na redução do potencial de acúmulo de sulfeto }\end{array}$ & Diminui $\mathrm{H}_{2} \mathrm{~S}_{\text {aquoso }}$ no esgoto \\
\hline & $\begin{array}{l}\text { Velocidades de projeto }>2,5 \mathrm{~m} / \mathrm{s} \text { propiciam um efeito } \\
\text { autolimpante da camada de lodo em todo o sistema. }\end{array}$ & Diminui $\mathrm{H}_{2} \mathrm{~S}_{\text {aquoso }}$ no esgoto \\
\hline & $\begin{array}{l}\text { Para velocidades de projeto }>3,0 \mathrm{~m} / \mathrm{s} \text {, é necessário um estudo } \\
\text { de dosagem para tornar o concreto resistente à abrasão }\end{array}$ & Elimina $\mathrm{H}_{2} \mathrm{~S}_{\text {aquoso }}$ no esgoto \\
\hline
\end{tabular}

expressiva de cloretos e sulfatos, e que $\mathrm{o} \mathrm{pH}$ deve ser próximo do neutro $(\mathrm{pH}$ 7,2), (Tabela 1).

Portanto, não deve ser esperada nenhuma desagregação na cobrimento do concreto abaixo do nível mínimo do esgoto. A Tabela 2 diferencia as três zonas da camada de lodo nas quais o $\mathrm{H}_{2} \mathrm{~S}_{\text {aquoso }}$ se forma (Wu, Hu e Liu 2018).
A quantidade de $\mathrm{H}_{2} \mathrm{~S}_{\text {aquoso }}$ no esgoto que pode ser emitido da camada de lodo depende diretamente do nível de oxigênio dissolvido (OD) no esgoto. A Tabela 3 apresenta um resumo dos fatores que afetam a formação de $\mathrm{H}_{2} \mathrm{~S}_{\text {aquoso }}$ no esgoto (Wu, Hu e Liu 2018).

Constatou-se que toda a superfí- cie que apresenta desagregação está acima do nível mínimo do esgoto, concentrando-se na área de respingos e variação do nível do efluente. A Tabela 4 traz os fatores que afetam a liberação de $\mathrm{H}_{2} \mathrm{~S}_{\text {gasoso }}$ no ar $(\mathrm{Wu}$, Hu e Liu 2018).

A presença de turbulência é um dos fatores que aceleram o processo

\section{Tabela 4 - Fatores que afetam a liberação de $\mathrm{H}_{2} \mathrm{~S}_{\text {gasoso }}$ no ar}

\begin{tabular}{|c|c|c|c|}
\hline Fator & \multicolumn{2}{|c|}{ Mecanismo } & Influência \\
\hline \multirow{3}{*}{ pH do esgoto } & \multirow{3}{*}{$\begin{array}{l}\mathrm{O}_{2} \mathrm{~S} \text { dissolvido pode existir como } \mathrm{H}_{2} \mathrm{~S}_{\text {aquoso }} \\
\text { e HS- no esgoto, dependendo do valor de } \mathrm{pH}\end{array}$} & $\mathrm{pH}<6 \rightarrow 100 \%$ de $\mathrm{H}_{2} \mathrm{~S}$ aquoso & Aumenta $\mathrm{H}_{2} \mathrm{~S}_{\text {gasoso }}$ no ar \\
\hline & & $6<\mathrm{pH}<9$ & pH típico do esgoto \\
\hline & & $\mathrm{pH}>9 \rightarrow 100 \%$ de HS- & Diminui $\mathrm{H}_{2} \mathrm{~S}_{\text {gasoso }}$ no ar \\
\hline $\begin{array}{l}\text { Turbulência no } \\
\text { fluxo do esgoto }\end{array}$ & \multicolumn{2}{|c|}{$\begin{array}{l}\text { Locais com forte turbulência agravam diretamente o processo de liberação do } \mathrm{H}_{2} \mathrm{~S}_{\text {aquoso }} \\
\text { no esgoto para a liberação do } \mathrm{H}_{2} \mathrm{~S}_{\text {gasoso }} \text { para a interface atmosfera }\end{array}$} & Aumenta $\mathrm{H}_{2} \mathrm{~S}_{\text {gasoso }}$ no ar \\
\hline $\begin{array}{l}\text { Temperatura } \\
\text { do esgoto }\end{array}$ & \multicolumn{2}{|c|}{$\begin{array}{l}0 \text { aumento da temperatura favorece a liberação na forma de } \mathrm{H}_{2} \mathrm{~S}_{\text {gasosos }} \text {, } \\
\text { pois reduz a solubilidade do } \mathrm{H}_{2} \mathrm{~S}_{\text {aquoso }} \text { no esgoto }\end{array}$} & Aumenta $\mathrm{H}_{2} \mathrm{~S}_{\text {gasoso }}$ no ar \\
\hline
\end{tabular}




\begin{tabular}{|c|c|c|}
\hline Fator & Mecanismo & Influência \\
\hline Carbonatação & $\begin{array}{l}\text { A carbonatação reduz o pH do cobrimento do concreto, consumindo o hidróxido de cálcio alcalino, } \\
\text { que favorece a colonização do concreto por microrganismos }\end{array}$ & $\begin{array}{l}\text { Aumenta } \mathrm{H}_{2} \mathrm{SO}_{4} \text { biogênico } \\
\text { no concreto }\end{array}$ \\
\hline \multirow{3}{*}{$\begin{array}{l}\text { Umidade relativa } \\
\qquad(\mathrm{UR})\end{array}$} & UR > 87\% é o valor mínimo necessário para que as BOS estejam ativas & \multirow{3}{*}{$\begin{array}{l}\text { Aumenta } \mathrm{H}_{2} \mathrm{SO}_{4} \text { biogênico } \\
\text { no concreto }\end{array}$} \\
\hline & $\begin{array}{l}\text { UR entre } 85 \% \leftrightarrow 95 \% \text {, necessária para as reações químicas de oxidação do sulfeto, } \\
\text { e } 0 \text { desenvolvimento das atividades das BOS }\end{array}$ & \\
\hline & $\begin{array}{l}\text { UR entre } 95 \% \leftrightarrow 100 \% \text {, na condição de saturação dos poros com água, } \\
\text { o pH do cobrimento do concreto é reduzido mais significativamente }\end{array}$ & \\
\hline \multirow{3}{*}{$\begin{array}{l}\text { Temperatura } \\
\text { atmosférica }\end{array}$} & Temperaturas abaixo de $15,6^{\circ} \mathrm{C}$ inibe a atividade metabólica das BOS & \multirow{3}{*}{$\begin{array}{l}\text { Aumenta } \mathrm{H}_{2} \mathrm{SO}_{4} \text { biogênico } \\
\text { no concreto }\end{array}$} \\
\hline & $\begin{array}{c}\text { Temperaturas entre } 15^{\circ} \mathrm{C} \leftrightarrow 20^{\circ} \mathrm{C} \text {, aumentam as atividades microbianas, com consequente } \\
\text { aumento da geração de } \mathrm{H}_{2} \mathrm{SO}_{4}\end{array}$ & \\
\hline & A taxa de oxidação do $\mathrm{H}_{2} \mathrm{~S}_{\text {gasoso }}$ a $25^{\circ} \mathrm{C}$ pode ser $15 \%$ maior do que aquela a $20{ }^{\circ} \mathrm{C}$ & \\
\hline Matéria orgânica & $\begin{array}{l}\text { A maior concentração de nutrientes e umidade se situa sobre a superfície do concreto próximo ao } \\
\text { nível do efluente devido a influência da zona de respingo. Desta maneira, esta área comumente } \\
\text { apresenta corrosão/degradação mais severa devido a maior atuação da atividade bacteriana }\end{array}$ & $\begin{array}{l}\text { Aumenta } \mathrm{H}_{2} \mathrm{SO}_{4} \text { biogênico } \\
\text { no concreto }\end{array}$ \\
\hline
\end{tabular}

de liberação do $\mathrm{H}_{2} \mathrm{~S}_{\text {aquoso }}$ do efluente para a atmosfera. Portanto, quanto maior a turbulência, maior é a liberação do $\mathrm{H}_{2} \mathrm{~S}_{\text {gasoso }}$. O aumento da temperatura é um outro fator que favorece a liberação na forma $\mathrm{H}_{2} \mathrm{~S}_{\text {gasoso. }} \mathrm{A}$ Tabela 5 traz fatores que afetam a geração de $\mathrm{H}_{2} \mathrm{SO}_{4}$ biogênico no cobrimento do concreto (Wu, Hu e Liu 2018).

\subsection{Análise química do concreto de testemunhos extraídos}

Uma análise química típica da coleta de testemunhos da parede contaminada para determinação de teores de cloretos e sulfatos solúveis presentes no cobrimento do concreto, que podem ser capazes de levar à corrosão das armaduras e à deterioração do concreto, tem seus resultados apresentados na Tabela 6.

A análise dos resultados obtidos permite constatar que os teores de cloretos e sulfatos nas amostras apresentam-se dentro dos limites admissíveis por norma.

\subsection{Análise petrográfica de testemunhos extraídos}

Foi feita uma análise petrográfica típica de corpos de prova extraídos dos locais afetados, para a confecção das lâminas delgadas, com o intuito de caracterizar a interface entre a região contaminada e a região do concreto aparentemente sã. A análise petrográfica

deve identificar quatro zonas distintas, como na Figura 2.

i. Contaminação primária: a primeira zona esbranquiçada, com espessura $500 \mu \mathrm{m}$ a 2,0 mm, mais externa,

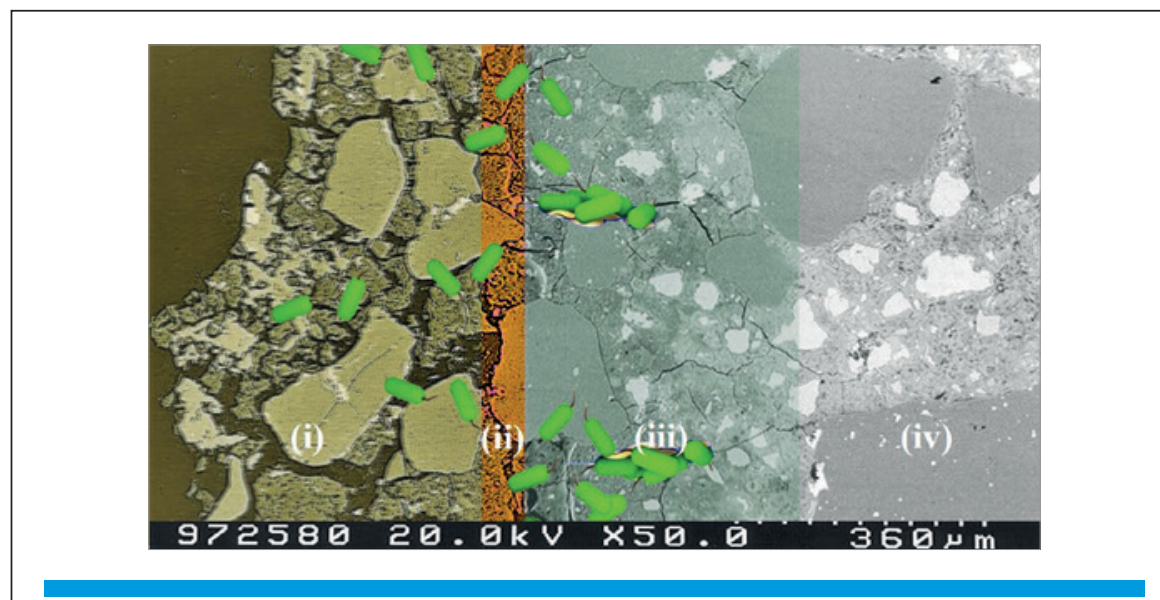

Figura 2

Microfotografia típica identifica quatro zonas distintas na análise petrográfica na interface entre a região aparentemente sã e a região afetada (biofilme aeróbico com BOS)

Tabela 6 - Determinação dos teores de cloretos e sulfatos no cobrimento do concreto nas paredes

\begin{tabular}{|c|ccc|}
\hline \multicolumn{2}{|c}{ Ambiente agressivo } & Resultados & Referência \\
\hline $\begin{array}{c}\text { Concentração } \\
\text { de cloretos }\end{array}$ & Totais & $0,02 \%$ & NBR 12655:2015 \\
\hline $\begin{array}{c}\text { Concentração } \\
\text { de sulfatos }\end{array}$ & Sobre a massa de cimento & $0,1 \%$ & $<0,15 \%$ smc \\
\hline & Solúveis & $0,6 \%$ & Decreto . 407/71 \\
\hline
\end{tabular}




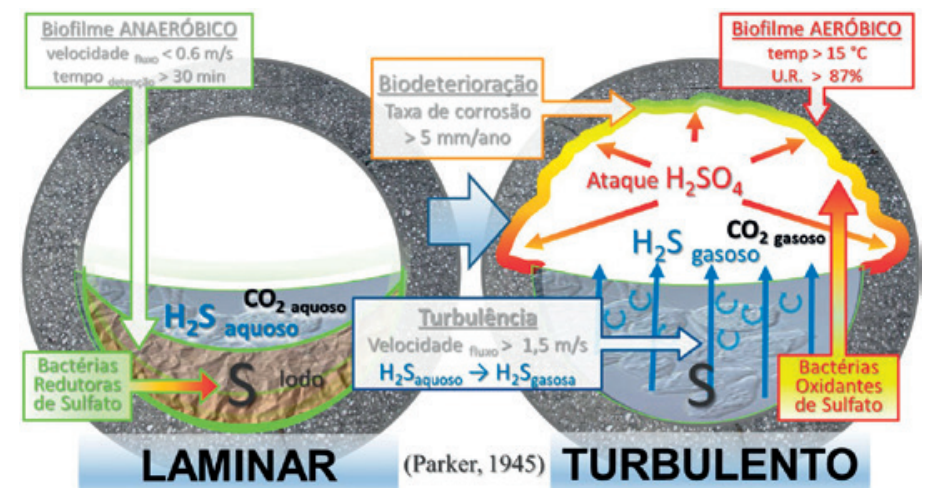

Figura 3

Processo de formação dos biofilmes anaeróbicos e aeróbicos que resulta na formação do ácido sulfúrico $\left(\mathrm{H}_{2} \mathrm{SO}_{4}\right)$ biogênico, para compreender a antibiose e estanqueidade do aditivo cristalino antimicrobiano (adaptado de Parker, 1945)

apresenta substituição da pasta por material cripto a microcristalino de birrefringência baixa, possível gipsita e etringita (temp. $>15^{\circ} \mathrm{C}$ ) / taumasita (temp. $<15^{\circ} \mathrm{C}$ ), em textura semeIhante a "argamassa", pontualmente carbonatada (biofilme aeróbico com colonização das bactérias oxidantes de sulfato);

ii. Interface da contaminação primária/secundária: a segunda zona intermediária, com espessura tes para as bactérias); de $100 \mu \mathrm{m}$ a 2,0 mm, apresenta substituição parcial da pasta, em tons avermelhados, com impregnação de hidróxidos de ferro e possível matéria orgânica (nutrien-

iii. Contaminação secundária: a terceira zona, com espessura entre 0 a 100 um, é uma zona carbonatada com tons amarelados, descontínua, com aumento da microporosidade, na interface com o concreto

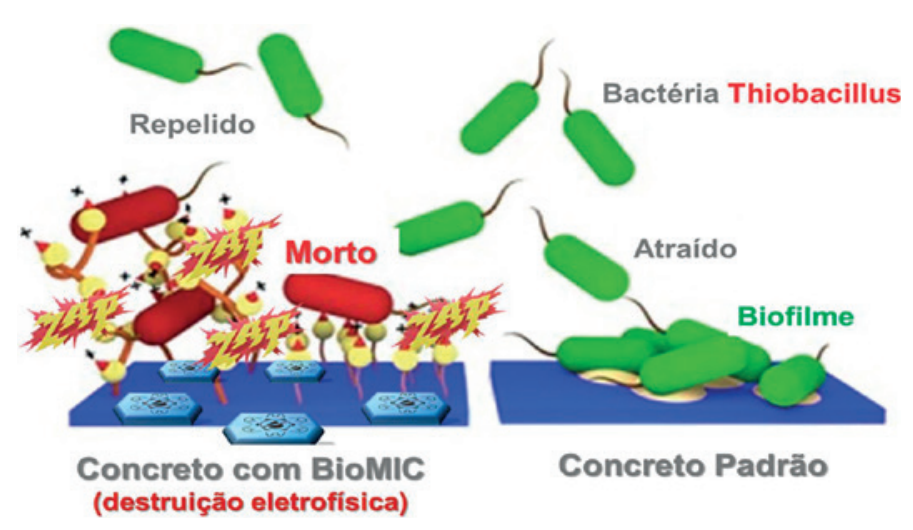

Figura 4

0 composto mineral bioativo antimicrobiano emite íons que rompem a membrana celular das bactérias, através de um mecanismo de antibiose eletrofísico, que faz parte da matriz do concreto e é resistente à lixiviação aparentemente não atacado (impregnação das bactérias oxidantes nas microfissuras);

iv. A quarta zona apresenta o aspecto geral da pasta aparentemente não atacada, com presença abundante de portlandita dispersa na pasta e na interface pasta-agregado e núcleos anidros de clínquer, por vezes evidenciando halo de reação e abundância de escória com duas diferentes composições, sendo uma incolor-amarelada e menos reativa e outra preto-esverdeada mais reativa - possível presença de sílica ativa na pasta.

\subsection{Diferentes locais para a} formação do ácido sulfúrico biogênico

É de grande importância compreender os diferentes locais e áreas, onde são formados $\mathrm{O}_{2} \mathrm{~S}_{\text {aquoso }}$ e a sua oxidação para $\mathrm{H}_{2} \mathrm{SO}_{4}$ biogênico (Figura 3), para prevenir e mitigar a formação dos biofilmes anaeróbicos e aeróbicos que resultam na formação do $\mathrm{H}_{2} \mathrm{SO}_{4}$ biogênico, através da colonização por BRS e BOS.

A mudança do fluxo LAMINAR para um TURBULENTO é o mecanismo de gatilho, que acelera o processo de liberação do $\mathrm{H}_{2} \mathrm{~S}_{\text {aquoso }}$ e $\mathrm{CO}_{2}$ aquoso' volatilizados sobre a linha do efluente, onde $\mathrm{O}_{2} \mathrm{~S}_{\text {gasoso }}$ e $\mathrm{CO}_{2}$ gasoso tendem a condensar-se sobre a parede úmida do concreto, em locais onde a umidade relativa está acima de $87 \%$, diminuindo e neutralizando o pH desta superfície de concreto, de forma abiótica, até um pH $\approx 5$ ao longo do tempo.

Nos trechos nos quais o fluxo do esgoto é TURBULENTO, e na presença de oxigênio, nutrientes e umidade, as 
superfícies de concreto, acima da linha do esgoto, possibilitam a colonização de microrganismos aeróbicos formadores de biofilme a partir da redução do $\mathrm{pH}$ a valores abaixo a 9. Dessa forma, a partir desse estágio, o sulfeto de hidrogênio $\mathrm{H}_{2} \mathrm{~S}_{\text {gasoso }}$ que se condensar sobre a superfície da parede de concreto está sujeito a múltiplos estágios de oxidação através das bactérias oxidantes de sulfato (ex. Thiobacillus), transformando-o em ácido sulfúrico $\mathrm{H}_{2} \mathrm{SO}_{4}$ biogênico. Sob tais condições, tanto o concreto quanto o aço estão expostos a elevadas taxas de deterioração do concreto e a corrosão da armadura.

\subsection{Antibiose do aditivo cristalino antimicrobiano}

$\mathrm{O}$ aditivo cristalino (CA) redutor de permeabilidade, em conjunto com o aditivo antimicrobiano (CA-A), é exclusivamente formulado para a proteção integral de estruturas de saneamento de concreto em condições severas de esgoto com altos níveis de $\mathrm{H}_{2} \mathrm{~S}$, que causam a corrosão induzida por microrganismos. Combina uma proteção antimicrobiana potente, juntamente com a tecnologia de impermeabilização por cristalização do concreto, que estimula quimicamente a autocicatrização de fissuras de até 0,5 mm, e forma permanentemente uma estrutura cristalina não solúvel dentro dos poros e capilaridades do concreto, bem como compostos minerais bioativos na matriz de concreto (Takagi, et al. 2018).

O composto mineral bioativo antimicrobiano emite íons, com fortes cargas positivas, que atrai as cargas negativas presentes na membrana celular das bactérias, e depois, através de um mecanismo de antibiose

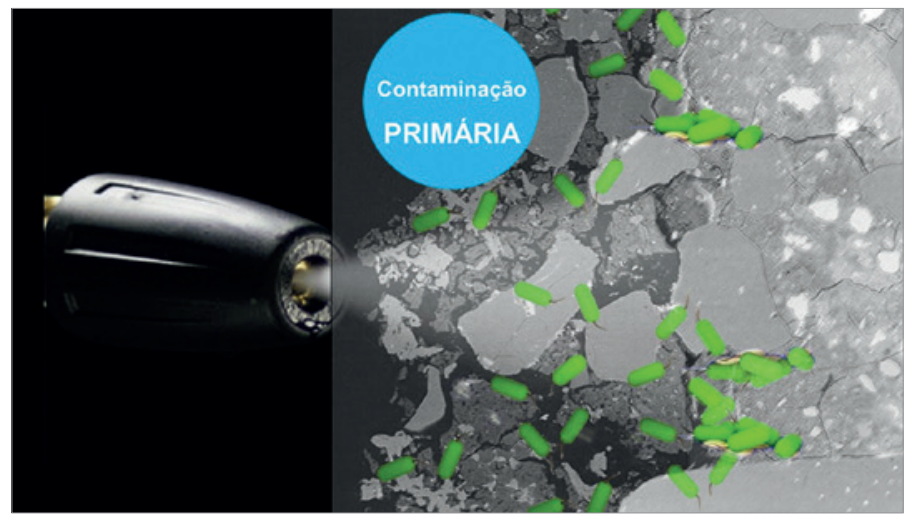

Figura 5

Antes de iniciar as etapas de recuperação, deve-se eliminar a camada de contaminação primária com hidrojateamento de alta pressão com 8.000 libras $/$ pol $^{2}$ efetivas (550 bar), com água potável e detergente alcalino

eletrofísico especial, destrói a célutempo e permanece ativa no concreto (Figura 4).

la de dentro para fora rompendo as paredes celulares dos microrganismos que convertem o sulfeto de hidrogênio $\left(\mathrm{H}_{2} \mathrm{~S}\right)$, em ácido sulfúrico biogênico $\left(\mathrm{H}_{2} \mathrm{SO}_{4}\right)$. $\mathrm{O}$ aditivo cristalino antimicrobiano é uma solução permanente; faz parte da matriz de concreto e é resistente à lixiviação. A eficácia da mistura antimicrobiana não diminui com o

\section{REABILITAÇÂO DA ESTRUTURA BIODETERIORADA}

Deve-se relacionar, no projeto de reabilitação, a escolha do material de reconstituição dosada com o aditivo cristalino e antimicrobiano, e o revestimento antiácido protetor e impermeável.

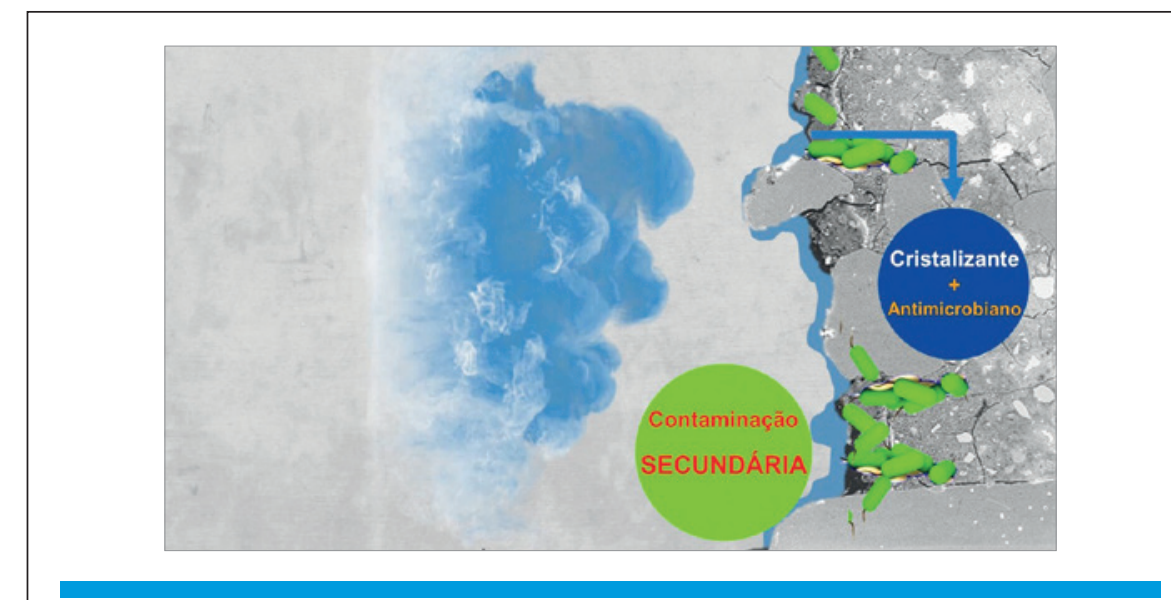

Figura 6

Pintura cristalizante dosada com o aditivo cristalino antimicrobiano, para selar as microfissuras e microporosidades, inibir e prevenir contra o crescimento de bactérias, minimizando o potencial de contaminação secundária e estendo a durabilidade da recuperação 


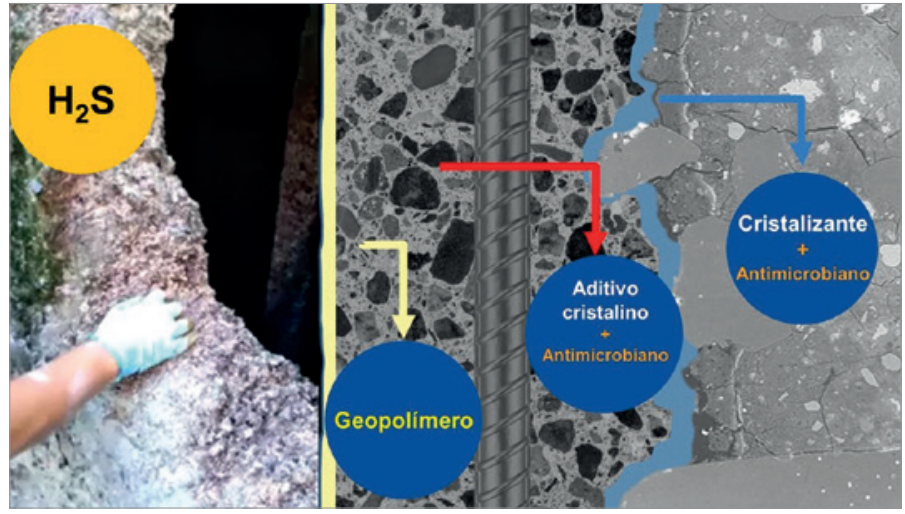

Figura 7

Após o hidrojateamento de 8.000 libras $/$ pol $^{2}$, aplicação de ponte de aderência com 0 aditivo cristalino antimicrobiano, recuperar a seção perdida da parede com a projeção da argamassa de reparo aditivada com o aditivo cristalino antimicrobiano

\section{I Limpeza da contaminação primária do substrato}

Para a limpeza do substrato de estruturas de concreto afetadas por biodeterioração, recomenda-se efetuar um hidrojateamento de alta pressão com 8.000 libras/pol² efetivas (550 bar) (Figura 5), com solução de água potável e detergente alcalino.

\subsection{Pintura inibidora da contaminação secundária do substrato}

Após a limpeza da contaminação primária, essas regiões também deverão ser receber o tratamento para a proteção contra a contaminação secundária, que consiste em uma reinfecção bacteriológica que pode acometer o espaço entre a recuperação e o subs- trato de concreto. Uma pintura cristalizante dosada com o aditivo cristalino antimicrobiano, para selar as microfissuras e microporosidades, é necessária para inibir e prevenir contra o crescimento de bactérias, minimizando o potencial de contaminação secundária e estendendo a durabilidade da recuperação (Figura 6).

\subsection{Reparos generalizados com material antimicrobiano}

Ao final da limpeza, deverá ser feita criteriosa inspeção visual, remover a corrosão das armaduras existentes, complementar a armadura por traspasse quando a perda de seção da barra de aço for superior a 10\% de seu diâmetro original, e a reconstituição deverá ser executada conforme descrito na Figura 7.

O material a ser aplicado deverá ser resistente aos sulfatos (RS). Como referência inicial para o estudo de dosagem de um concreto moldado ou projetado, com relação água/aglomerante a/c < 0,45 , recomenda-se o uso de cimento CPIII 40 RS com a adição de 8 \% de sílica ativa, e 0,8 \% de aditivo cristalizante sobre a massa de cimento (smc) e o aditivo antimicrobiano dosado na proporção de $5 \mathrm{~L} / \mathrm{m}^{3}$.

O revestimento de geopolímero, que é um material inovador, com propriedades de elevada resistência mecânica e dureza superficial, pode desenvolver propriedades de resistência química contra o ácido sulfúrico $\mathrm{H}_{2} \mathrm{SO}_{4}$, quando ativado pelo próprio ASB produzido pelas BOS e aumentar a durabilidade da reabilitação.

\section{CONCLUSÕES}

Muitos dos procedimentos de reparo definidos neste artigo foram inspirados nos procedimentos odontológicos de remoção da contaminação primária da "cárie do dente", e a utilização dos aditivos antimicrobianos como uma estratégia sistêmica para mitigar e evitar a contaminação secundária, ou a reinfecção persistente que pode comprometer a durabilidade das estruturas de saneamento. Uma condição para o "desenvolvimento do conhecimento" é hoje, a multidisciplinariedade, que reúne diversas áreas de conhecimento, além da engenharia civil, como a biologia e a odontologia.

\section{DREFERÊNCIAS BIBLIOGRÁFICAS}

[1] Bonifácio, Sávio Nunes, Cristiano Martins Quintão, e Frieda Keifer Cardoso. "Building, Fallen Down and Recovery of Tanks of Ferrocement in Waste Water Treatment Plants." The $13^{\text {th }}$ International Symposium on Ferrocement Andthin Fiber Reinforced Inorganic Matrices. Lyon: França, 2021

[2] Quintão, Cristiano Martins, Daniel Rodrigues Rezende Neves, Dayana Cristina Sllva Garcia, e Maria Teresa Paulino Aguilar. "Inspeção, diagnóstico, projeto e obra de recuperaçãa de estruura de concreto em uma estação de tratamento de esgoto." Revista Técnica IBAPE-MG, Setembro de 2020: 42 - 43.

[3] Takagi, Emilio Minoru, Maryangela Geimba Lima, Paulo Helene, e Ronaldo Alves Medeiros-Júnior. "Self-healing of self-compacting concretes made with blast furnace slag cements activated by crystalline admixture." International Journal of Materials and Product Technology, 2018: 169-186.

[4] Wu, L; Hu, C.; Liu, W.V. The Sustainability of Concrete in Sewer Tunnel - A Narrative Review of Acid Corrosion in the City of Edmonton, Canada. Sustainability 2018, 10, 517. 